\title{
Suprachiasmatic translamina terminalis corridor used in endoscopic endonasal approach for resecting third ventricular craniopharyngioma
}

\author{
Ye Gu, MD, ${ }^{1}$ Xiaobiao Zhang, MD, ${ }^{1,2}$ Fan Hu, MD, ${ }^{1,2}$ Yong Yu, MD, PhD, ${ }^{1}$ Tao Xie, MD, ${ }^{1}$ \\ Chongjing Sun, MD, ${ }^{1}$ and Wensheng $\mathrm{Li}, \mathrm{PhD}^{3}$
}

\begin{abstract}
1Department of Neurosurgery, Zhongshan Hospital, Fudan University; ${ }^{2}$ Shanghai Key Lab of Medical Image Computing and Computer-Assisted Intervention, Shanghai Medical College; and ${ }^{3}$ Department of Anatomy/Digital Medical Research Center, Shanghai Medical College, Fudan University, Shanghai, People's Republic of China
\end{abstract}

\begin{abstract}
OBJECT The translamina terminalis corridor was used in the transcranial anterior route to treat third ventricular craniopharyngioma (TVC), which presents a challenge to neurosurgeons. The endoscopic endonasal approach (EEA) has recently been used to treat craniopharyngiomas. However, there are few reports of the EEA being used to treat TVC. The authors' novel surgical approach of treating selected TVC by the endoscopic endonasal route via the suprachiasmatic translamina terminalis (STLT) corridor is described.
\end{abstract}

METHODS In this single-center study, the EEA via the STLT corridor was used to resect TVC with great upper and anterior extension causing bulged lamina terminalis, and TVC with a residual upper compartment, after routine infrachiasmatic transmetastalk corridor resection.

RESULTS The STLT corridor was used in 3 patients. Gross-total resection was achieved in all cases. One patient achieved visual improvement, and the other 2 patients showed partial visual improvement. Leakage of CSF occurred in 1 patient. Postoperative hormone replacement therapy was required in all patients.

CONCLUSIONS The STLT corridor is a complementary minimally invasive corridor used in the EEA for treating selected TVC. The STLT alone or combined with infrachiasmatic transmetastalk corridors should be selected depending on the size of suprachiasmatic and infrachiasmatic space.

http://thejns.org/doi/abs/10.3171/2015.1.JNS132842

KEY WORDS craniopharyngioma; endoscopic endonasal approach; third ventricle; lamina terminalis; surgical technique

$\mathrm{T}$ HIRD ventricular craniopharyngiomas (TVCs) include both strictly intraventricular craniopharyngiomas, lying wholly within an intact third ventricle, and lesions that are not strictly intraventricular, which are located partly within the third ventricle and partly in the suprasellar area.,25 The TVC is among the most challenging of the lesions that confront neurosurgeons, due to both its deep location and its tendency to adhere to vital surrounding structures. The translamina terminalis (TLT) approach was reported as a valid choice for the removal of lesions involving the third ventricle, without major se- quelae related to the surgical approach in which bifrontal craniotomy ${ }^{8}$ or supraorbital craniotomy ${ }^{20}$ is used, and as a complementary approach in extended transsphenoidal surgery for suprasellar craniopharyngiomas. ${ }^{17}$

The endoscopic endonasal approach (EEA) has been used to treat suprasellar craniopharyngioma in some institutions and is considered to be an alternative minimally invasive surgery approach. ${ }^{4-7,9,10,12,13,19,21,22,27}$ Among suprasellar craniopharyngiomas treated via the EEA, the TVC subtype remains the most difficult to handle. The technique of resecting posterior clinoid ${ }^{14}$ or pituitary transpo-

ABBREVIATIONS EEA = endoscopic endonasal approach; GTR = gross-total resection; ITMS = infrachiasmatic transmetastalk; LT = lamina terminalis; OC = optic chiasm; PS = pituitary stalk; SIS = superior intercavernous sinus; STLT = suprachiasmatic translamina terminalis; TLT = translamina terminalis; TVC = third ventricular craniopharyngioma; TVF = third ventricle floor.

ACCOMPANYING EDITORIAL See pp 1163-1165. DOI: 10.3171/2014.6.JNS141129.

SUBMITTED December 23, 2013. ACCEPTED January 5, 2015.

INCLUDE WHEN CITING Published online February 27, 2015; DOI: 10.3171/2015.1.JNS132842.

DISCLOSURE The authors report no conflict of interest concerning the materials or methods used in this study or the findings specified in this paper. This article was funded by the Foundation of Shanghai Science and Technology Commission (134119a1202). 
sition ${ }^{16}$ to create more room may help manage TVCs with great upper and anterior extension. However, the technique can only be used by experienced surgeons because of the complicated procedures and potential risks. In this study, we report the application of the suprachiasmatic translamina terminalis (STLT) corridor in the EEA for resecting TVCs with great upper and anterior extension causing bulged lamina terminalis (LT), and TVCs with a residual upper compartment after infrachiasmatic transmetastalk (ITMS) corridor resection.

\section{Methods}

\section{Surgical Technique \\ General Exposure}

The surgical exposure of the suprasellar region, using a $0^{\circ}$, 18-cm-long, 4-mm-wide rigid endoscope (Karl Storz), was performed as described in the literature ${ }^{7,9,15}$ with neuronavigation (Excelim-04 image-guide system, Fudan Digital Medical Co.). A pedicle nasoseptal flap was raised and stored in the nasopharynx as reported before. ${ }^{11}$

\section{Tumor Resection Through the STLT Corridor}

A TVC with great upper and anterior extension often causes bulged LT; if the infrachiasmatic corridor is too narrow to expose the tumor, the STLT corridor may be selected for tumor removal. The LT could be opened safely after pushing the anterior communicating complex upward. A vertical incision was made so that the intraventricular portion of the tumor was exposed. Using a suction tube, tumor-grasping forceps, endoscopic scissors, or Cavitron ultrasonic surgical aspirator (CUSA, Söring $\mathrm{GmbH}$ ), the tumor was debulked and excised. Following sufficient intracapsular debulking and extracapsular dissection, the tumor capsule was entirely pulled out in piecemeal fashion. The intraventricular structures were presented.

\section{Tumor Resection Through the STLT Combined With the ITMS Corridor}

For TVCs with infrachiasmatic extension, care should be taken when opening the dura mater to prevent damage to the clingy optic chiasm (OC) and pituitary stalk (PS) or infundibulum. Due to its infrachiasmatic extension, the tumor was exposed directly after opening the arachnoid membrane. The PS or infundibulum was compressed forward, situated in the middle surface or in the lateral margin of the tumor or split. A vessel-like structure on the midline surface or lateral margin of the tumor could be seen, which was identified as squashed PS or infundibulum and its surrounding hypophyseal portal vessels, by the following procedure. The superior hypophyseal arteries, arising from the medial side of the supraclinoid portion of the internal carotid artery and passing medially to the PS, low margin of OC, and third ventricle floor (TVF), should always be preserved to avoid damage to vision and pituitary function. Thirty-degree and forty-five-degree lenses were used to detect whether there were any unintended residual tumors. If there is still a residual tumor beyond the visual field, the STLT corridor should be used. After the infrachiasmatic decompression of the tumor, the upward-displaced OC descended gradually, making more space in the suprachiasmatic corridor. The surgical procedure is the same as that described above. The STLT combined with the ITMS corridor was used for maximal tumor removal with minimal disturbance of the optic apparatus and intraventricular structures. It should be kept in mind that tumor resection is performed based on the need to protect preoperative neurological function; thus, subtotal tumor resection was permitted when inseparable adhesion between tumor and intraventricular structures was encountered.

\section{Cranial Base Reconstruction}

Cranial base reconstruction was completed in a multilayered fashion. Two pieces of fascia lata from the right thigh or artificial dura (Duragen, Integra LifeSciences) were placed between the dura and bone as inlay substitutions and outside the bone as outlay substitutions, respectively. The pedicle nasoseptal flap harvested at the beginning of the procedure was positioned to overlap the cranial defect. Efforts were made to ensure that the flap contacted the bony edges directly and completely to promote vascularization and seal. The sphenoid sinus was filled with autologous fat. Fibrin sealant (Shanghai RAAS blood products Co., Ltd.) was applied. A 12-Fr Foley balloon with 8-10 $\mathrm{ml}$ saline was then inserted into the nasal cavity to provide further support against flap migration. No nasal packing was needed. Given the high risk of CSF leakage due to the communication between the third ventricle and suprasellar cistern, lumbar drainage was performed on the 1st day after the operation and remained for 1 week.

\section{Results}

The STLT corridor was applied in 3 patients; grosstotal resection (GTR) was achieved in all of them. One patient experienced visual improvement; the other 2 patients showed partial visual improvement. No new anterior pituitary dysfunction or permanent diabetes insipidus was found. Leakage of CSF occurred in 1 patient. No intracranial infection or hydrocephalus was found. Postoperative hormone replacement therapy was required in 2 patients in the follow-up period. Tumor recurred at the 26th month of the follow-up period and resolved with Gamma Knife surgery in 1 patient. The details were described in Table 1.

\section{Illustrative Cases \\ Case 1}

This 31-year-old woman presented with amenorrhea, visual loss (right 20/40, left 20/50, full visual field), and headache. Preoperative hypothyroidism and hyperprolactinemia were found. Admission MRI showed a solid $3.6 \times$ $3.0 \times 2.8-\mathrm{cm}$ TVC extending to the interpeduncular cistern inferiorly and compressing the fornix and bilateral foramen of Monro superiorly and the LT anteriorly. Obstructive hydrocephalus was also found. Tumor removal began with the ITMS corridor, but there was still a hidden tumor beyond the surgical field. The STLT corridor was used to remove the residual tumor with a straight view so that GTR was achieved (Video 1). 
VIDEO 1. Intraoperative video of the patient in Case 1. Copyright Ye Gu. Published with permission. Click here to view with Media Player. Click here to view with Quicktime.

The OC and PS were intact. Visual acuity was improved in the right eye (20/25) but worsened in the left eye (20/200); the visual field remained full. Transient diabetes insipidus was found, and recovery was achieved with oral desmopressin. Hormone replacement therapy was initiated and sustained for 6 months. No CSF leakage was observed. Postoperative MRI showed GTR. In the last follow-up study no tumor recurrence was found, and the worsened visual acuity remain unchanged. Results of the endocrine examination were normal (Figs. 1 and 2).

\section{Case 3}

This 41-year-old man presented with visual loss (right 20/80, left 20/63, full visual field) and hypogonadism. Admission MRI demonstrated a solid $3.1 \times 2.8 \times 2.7-\mathrm{cm}$ TVC causing a bulged LT and obstructive hydrocephalus. The STLT corridor was applied, and GTR was achieved. Leakage of CSF was found, and endoscopic endonasal repair was performed. The hydrocephalus was not resolved, so ventriculoperitoneal shunting was performed. Improvement of visual acuity was achieved (right 20/40, left 20/50, full visual field). Postoperative MRI confirmed the GTR. Hormone replacement therapy was required, and no tumor recurrence was found in the last follow-up study (Fig. 3).

\section{Discussion}

\section{Indications and Contraindications}

The selection of an optimal surgical approach for lesions in and around the third ventricle is dependent on the origin and growing direction of the lesions. Surgical access must provide adequate exposure while minimizing unintended injury to the brain and its vascular supply. Many third ventricle lesions can be approached by several different routes, and the final selection is often determined by the surgeon's experience and comfort level. Today, endoscopy, which offers panoramic visualization and adequate room for maneuvering, is widely used along with the extended transsphenoidal approach. Although it has the disadvantage of increasing the rate of CSF leakage, many advantages of the EEA have been described, including avoiding brain retraction, minimal manipulation of the optic apparatus, direct visualization, better protection of surrounding neurovascular structures, greater postoperative comfort, and shorter hospitalization, compared with the transcranial approach or the transsphenoidal approach with microsurgery. Those advantages are similar when comparing the endoscopic endonasal TLT approach to the transcranial TLT approach. Moreover, the potential risk of opening the frontal sinus and damage to the olfactory nerve in the frequently used frontal craniotomy is eliminated.

The TLT approach is a valid surgical choice in resecting increased risks of visual and hormonal deficits. ${ }^{1,8,16,20,23,26,28}$ The STLT corridor has been considered a complementary route affording complete resection when using a microsurgical extended transsphenoidal approach. ${ }^{17}$ Recently, the craniopharyngiomas via the transcranial approach without

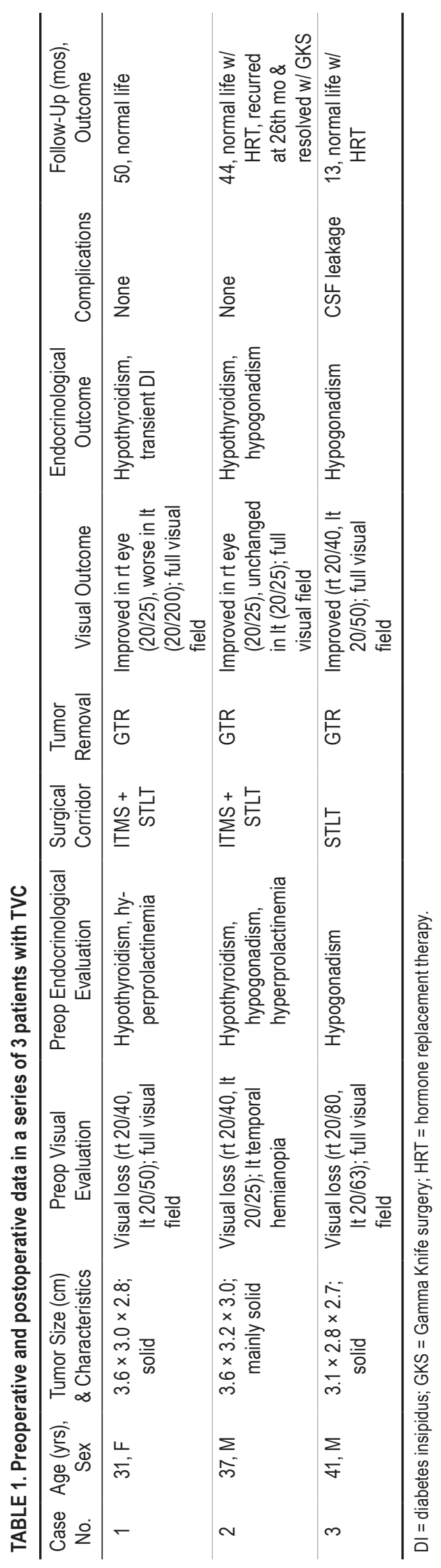




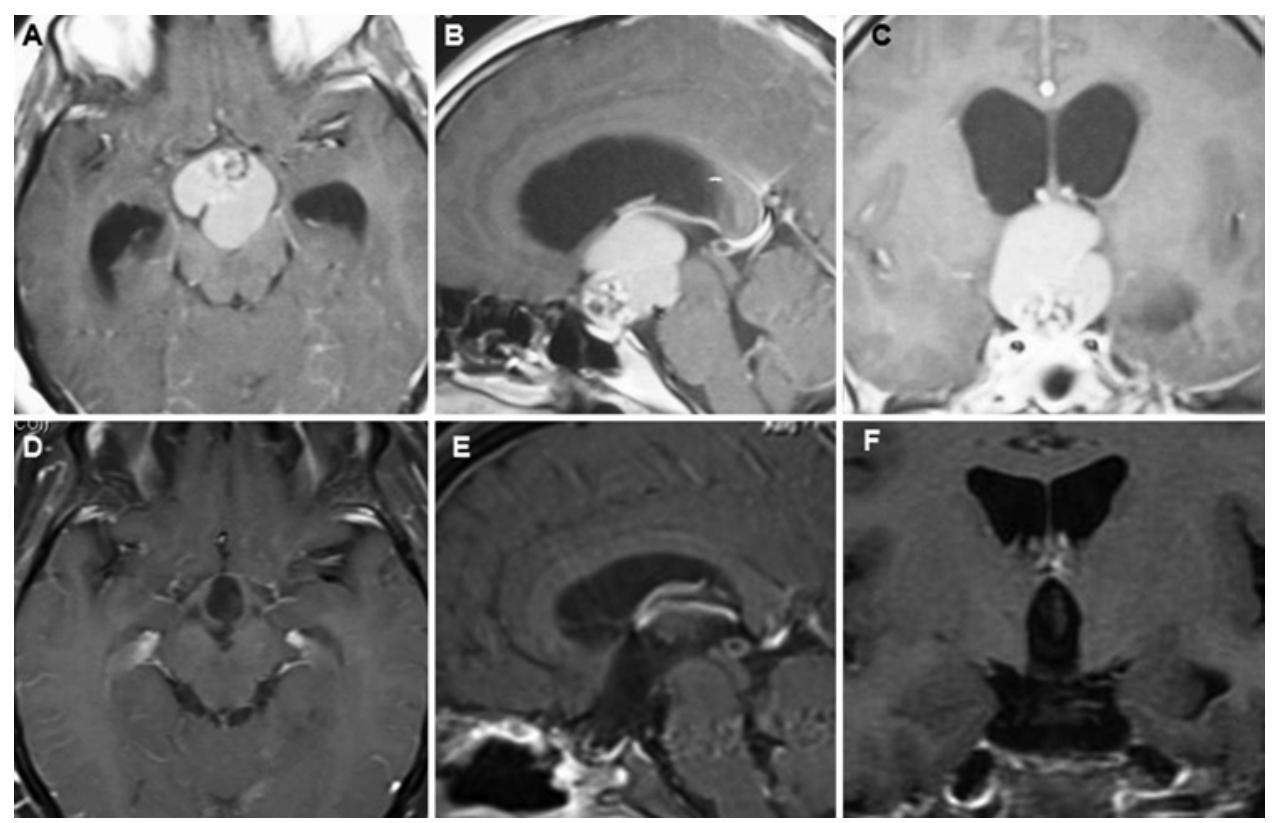

FIG. 1. Illustrative Case 1. Preoperative MR images obtained in this patient demonstrated a solid craniopharyngioma with infrachiasmatic extension, obviously bulged LT, and hydrocephalus (A-C). Postoperative MR images showed total tumor removal and no recurrence after surgery (D-F).
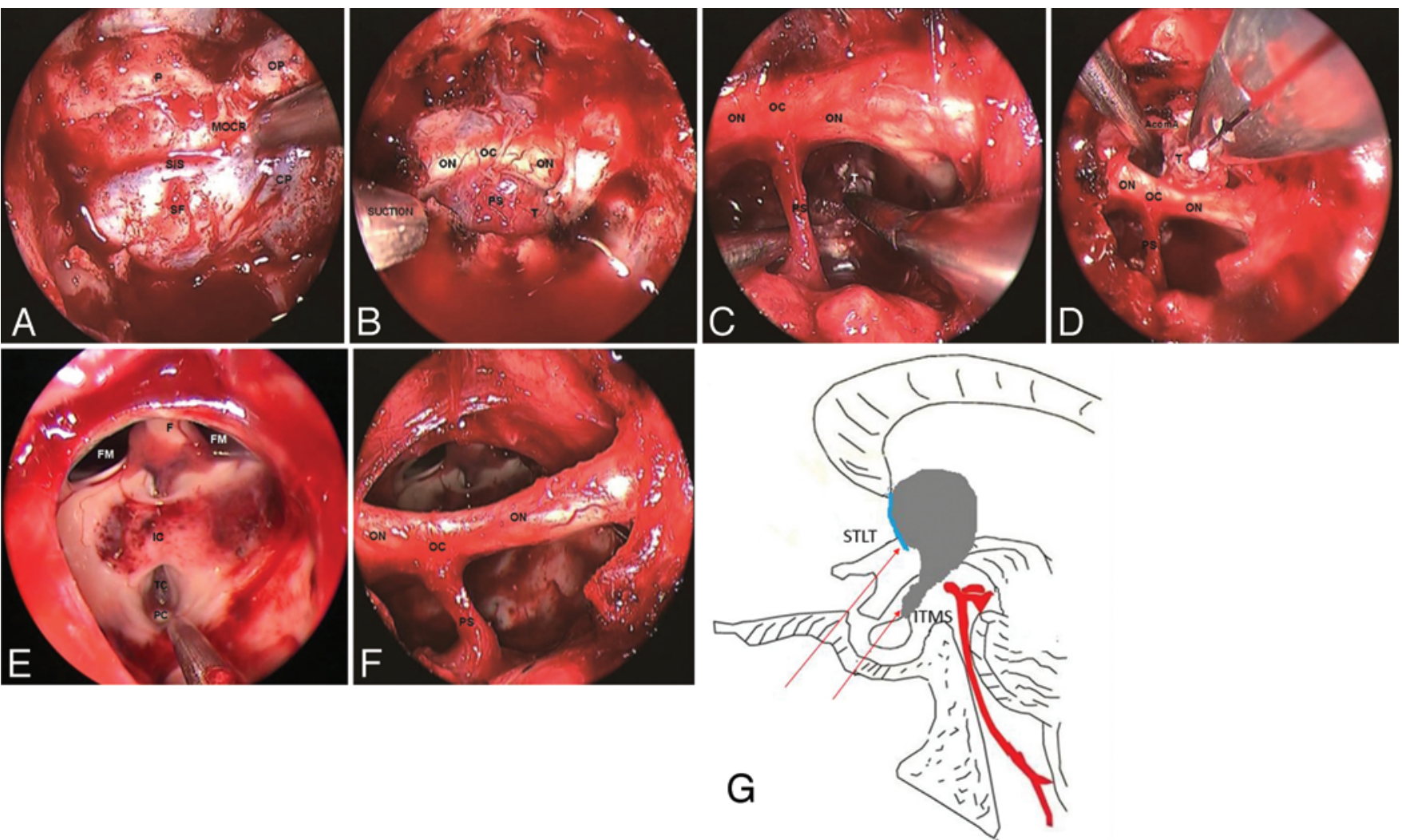

FIG. 2. Illustrative Case 1. Intraoperative images. After bone removal and before dural opening (A), the tumor was found through the arachnoid membrane after dural opening (B) and resected piece by piece through the ITMS plus STLT corridors (C and D); intraventricular structures and suprasellar region were observed clearly after total tumor removal (E and $F)$. A schematic figure $(G)$ of the ITMS plus STLT corridors; blue represents LT and red represents the basilar artery. AcomA = anterior communicating artery; $\mathrm{CP}=$ carotid protuberance; $\mathrm{F}=$ fornix; $\mathrm{FM}=$ foramen of Monro; $\mathrm{IC}=$ interthalamic commissure; $\mathrm{MOCR}=$ medial opticocarotid recess; $\mathrm{ON}=$ optic nerve; $\mathrm{OP}=$ optic protuberance; $\mathrm{P}=$ planum sphenoidale; $\mathrm{PC}=$ posterior commissure; $\mathrm{SF}=$ sellar floor; $\mathrm{SIS}=$ superior intercavernous sinus; $\mathrm{T}=$ tumor; $\mathrm{TC}=$ tela choroidea. Figure is available in color online only. 

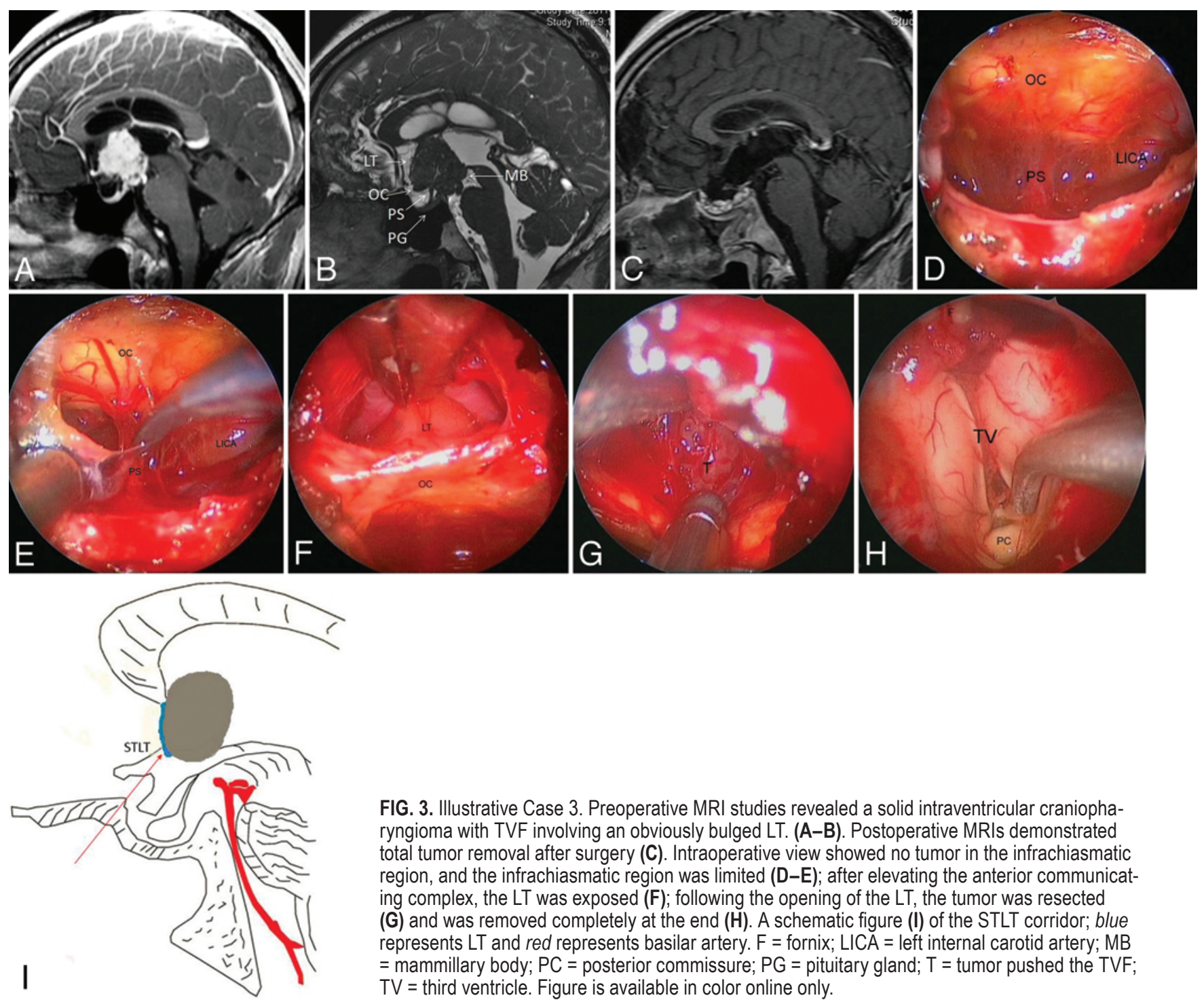

FIG. 3. Illustrative Case 3. Preoperative MRI studies revealed a solid intraventricular craniopharyngioma with TVF involving an obviously bulged LT. (A-B). Postoperative MRIs demonstrated total tumor removal after surgery (C). Intraoperative view showed no tumor in the infrachiasmatic region, and the infrachiasmatic region was limited (D-E); after elevating the anterior communicating complex, the LT was exposed (F); following the opening of the LT, the tumor was resected $(\mathbf{G})$ and was removed completely at the end $(\mathrm{H})$. A schematic figure (I) of the STLT corridor; blue represents $L T$ and red represents basilar artery. $F=$ fornix; $L I C A=$ left internal carotid artery; MB = mammillary body; $P C=$ posterior commissure; $P G$ = pituitary gland; $T$ = tumor pushed the TVF; TV $=$ third ventricle. Figure is available in color online only.

EEA has been reported as a safe and effective alternative for the treatment of certain craniopharyngiomas in locations ranging from the sellar region to the third ventricle without more lateral extension, after considering the degree of tumor removal, visual outcome, and endocrinological outcome. ${ }^{4-7,9,10,12,13,18,19,21,22,27}$ For TVCs the EEA still provides enough exposure of the remote ventricular region via the pre- and retrochiasmatic corridor; the latter corridor is completed through the ITMS and/or the STLT approach.

To our knowledge, a purely endoscopic TLT approach for TVC has not been reported. In this cohort, 2 patients with tumors invading the fornix underwent ITMS plus STLT routes. An intraoperative view showed that the ITMS corridor alone cannot provide complete exposure of the tumor or the roof of the third ventricle, and adds potential injury to the OC. One patient underwent a solely STLT route because the OC was displaced anteriorly and inferiorly, thus making a large suprachiasmatic space and pathological bulging of the LT, through which the tumor, primarily in the third ventricle and partly in the interpe- duncular cistern, was removed completely. In summary, the indications for selecting the STLT corridor are as follows: 1) the LT is elongated by the tumor whereas the infrachiasmatic space is limited for tumor removal; and 2) the tumor shows great superior extension or still has an invisible portion even after pulling it downward. However, not all TVCs were indications for the EEA; prominent lateral or superior invasion, no infra- and suprachiasmatic spaces, and a poorly pneumatized sphenoid sinus were major unfavorable factors.

\section{Postoperative Complications}

In our series of procedures, CSF leakage and visual impairment was observed to occur. The incidence of CSF leakage has been reduced dramatically to $0 \%-4.5 \%{ }^{24,30}$ due to progressive repairing techniques, such as multilayer repair and new materials; e.g., tissue-compatible dural substitutes. The vascularized nasoseptal flap and gasket-seal technique represent the newest reconstruction method, which we added in the later patients. The leakage point in 
our patient who had this complication was in the left upper margin, which represented the most remote area for a nasoseptal flap. Intracranial pressure should be avoided to prevent delayed postoperative CSF leakage. Visual impairment was reported in both the EEA cohort and the transcranial cohort. ${ }^{19}$

The OC receives blood supply from 3 vessel groups: the inferior aspect is fed by the anterior superior hypophyseal and posterior communicating arteries; the lateral aspect is fed directly by the ophthalmic segment of the internal carotid artery; and the superior aspect is fed mainly by the anterior cerebral and anterior communicating arteries. However, the blood supply of the OC was mainly delivered from the inferior side, and there was no superior supply in the central part, which prevented the TLT corridor from injuring the blood supply. ${ }^{3,29}$ Accordingly, the potential risk of injuring visual acuity may not be increased by extra manipulation in the suprachiasmatic region beside the infrachiasmatic space but by the excessive manipulation on the OC. It is inferred that the solely STLT corridor is favorable in protecting the OC. The factors that could cause optic injury include the following: 1) thermal damage ascribed to the drilling of the bone of the tuberculum sellae and medial opticocarotid recess; 2) excessive traction on the optic apparatus during tumor dissection; 3) damage to feeding arteries of the optic apparatus or vasospasm; and 4) compression of the optic nerve due to the overfilling of reconstruction materials. One patient reported unilateral visual worsening, although it improved in the contralateral side in this cohort. The visual impairment was primarily caused by excessive pulling of the optic nerve.

Although the STLT corridor was successfully used in 3 patients with TVC and achieved acceptably good outcomes, more cases and long-term outcomes are needed to enhance the clinical effectiveness of this approach.

\section{Conclusions}

The STLT corridor is a complementary minimally invasive corridor used in the EEA to treat selected TVCs. The STLT corridor alone or combined with ITMS corridors should be selected depending on the size of suprachiasmatic and infrachiasmatic space.

\section{References}

1. Abdou MS, Cohen AR: Endoscopic surgery of the third ventricle: the subfrontal trans-lamina terminalis approach. Minim Invasive Neurosurg 43:208-211, 2000

2. Behari S, Banerji D, Mishra A, Sharma S, Sharma S, Chhabra DK, et al: Intrinsic third ventricular craniopharyngiomas: report on six cases and a review of the literature. Surg Neurol 60:245-253, 2003

3. Bergland R: The arterial supply of the human optic chiasm. $\mathbf{J}$ Neurosurg 31:327-334, 1969

4. Campbell PG, McGettigan B, Luginbuhl A, Yadla S, Rosen M, Evans JJ: Endocrinological and ophthalmological consequences of an initial endonasal endoscopic approach for resection of craniopharyngiomas. Neurosurg Focus 28(4):E8, 2010

5. Cavallo LM, Prevedello DM, Solari D, Gardner PA, Esposito F, Snyderman CH, et al: Extended endoscopic endonasal transsphenoidal approach for residual or recurrent craniopharyngiomas. J Neurosurg 111:578-589, 2009
6. Cavallo LM, Solari D, Esposito F, Cappabianca P: The endoscopic endonasal approach for the management of craniopharyngiomas involving the third ventricle. Neurosurg Rev 36:27-38, 2013

7. de Divitiis E, Cappabianca P, Cavallo LM, Esposito F, de Divitiis O, Messina A: Extended endoscopic transsphenoidal approach for extrasellar craniopharyngiomas. Neurosurgery 61 (5 Suppl 2):219-228, 2007

8. Dehdashti AR, de Tribolet N: Frontobasal interhemispheric trans-lamina terminalis approach for suprasellar lesions. Neurosurgery 56 (2 Suppl):418-424, 2005

9. Frank G, Pasquini E, Doglietto F, Mazzatenta D, Sciarretta V, Farneti G, et al: Extend endoscopic transsphenoidal approach for craniopharyngioma. Neurosurgery 59 (1 Suppl 1):ONS75-ONS83, 2006

10. Gardner PA, Kassam AB, Snyderman CH, Carrau RL, Mintz $\mathrm{AH}$, Grahovac S, et al: Outcomes following endoscopic, expanded endonasal resection of suprasellar craniopharyngiomas: a case series. J Neurosurg 109:6-16, 2008

11. Hadad G, Bassagasteguy L, Carrau RL, Mataza JC, Kassam A, Snyderman CH, et al: A novel reconstructive technique after endoscopic expanded endonasal approaches: vascular pedicle nasoseptal flap. Laryngoscope 116:1882-1886, 2006

12. Jane JA Jr, Kiehna E, Payne SC, Early SV, Laws ER Jr: Early outcomes of endoscopic transsphenoidal surgery for adult craniopharyngiomas. Neurosurg Focus 28(4):E9, 2010

13. Kassam A, Snyderman CH, Mintz A, Gardner P, Carrau RL: Expanded endonasal approach: the rostrocaudal axis. Part I. Crista galli to the sella turcica. Neurosurg Focus 19(1):E3, 2005

14. Kassam AB, Gardner P, Snyderman C, Mintz A, Carrau R: Expanded endonasal approach: fully endoscopic, completely transnasal approach to the middle third of the clivus, petrous bone, middle cranial fossa, and infratemporal fossa. Neurosurg Focus 19(1):E6, 2005

15. Kassam AB, Gardner PA, Snyderman CH, Carrau RL, Mintz AH, Prevedello DM: Expanded endonasal approach, a fully endoscopic transnasal approach for the resection of midline suprasellar craniopharyngiomas: a new classification based on the infundibulum. J Neurosurg 108:715-728, 2008

16. Kassam AB, Prevedello DM, Thomas A, Gardner P, Mintz A, Snyderman C, et al: Endoscopic endonasal pituitary transposition for a transdorsum sellae approach to the interpeduncular cistern. Neurosurgery 62 (3 Suppl 1):57-74, 2008

17. Kitano M, Taneda M: Extended transsphenoidal surgery for suprasellar craniopharyngiomas: infrachiasmatic radical resection combined with or without a suprachiasmatic translamina terminalis approach. Surg Neurol 71:290-298, 2009

18. Komotar RJ, Starke RM, Raper DM, Anand VK, Schwartz TH: Endoscopic endonasal compared with microscopic transsphenoidal and open transcranial resection of craniopharyngiomas. World Neurosurg 77:329-341, 2012

19. Koutourousiou M, Gardner PA, Fernandez-Miranda JC, Tyler-Kabara EC, Wang EW, Snyderman CH: Endoscopic endonasal surgery for craniopharyngiomas: surgical outcome in 64 patients. J Neurosurg 119:1194-1207, 2013

20. Krishna V, Blaker B, Kosnik L, Patel S, Vandergrift W: Trans-lamina terminalis approach to third ventricle using supraorbital craniotomy: technique description and literature review for outcome comparison with anterior, lateral and trans-sphenoidal corridors. Minim Invasive Neurosurg 54:236-242, 2011

21. Laufer I, Anand VK, Schwartz TH: Endoscopic, endonasal extended transsphenoidal, transplanum transtuberculum approach for resection of suprasellar lesions. J Neurosurg 106:400-406, 2007

22. Leng LZ, Greenfield JP, Souweidane MM, Anand VK, Schwartz TH: Endoscopic, endonasal resection of craniopharyngiomas: analysis of outcome including extent of resection, 
cerebrospinal fluid leak, return to preoperative productivity, and body mass index. Neurosurgery 70:110-124, 2012

23. Maira G, Anile C, Colosimo C, Cabezas D: Craniopharyngiomas of the third ventricle: trans-lamina terminalis approach. Neurosurgery 47:857-865, 2000

24. Mascarenhas L, Moshel YA, Bayad F, Szentirmai O, Salek AA, Leng LZ, et al: The transplanum transtuberculum approaches for suprasellar and sellar-suprasellar lesions: avoidance of cerebrospinal fluid leak and lessons learned. World Neurosurg 82:186-195, 2014

25. Prabhu VC, Brown HG: The pathogenesis of craniopharyngiomas. Childs Nerv Syst 21:622-627, 2005

26. Silva PS, Cerejo A, Polónia P, Pereira J, Vaz R: Trans-lamina terminalis approach for third ventricle and suprasellar tumours. Clin Neurol Neurosurg 115:1745-1752, 2013

27. Stamm AC, Vellutini E, Harvey RJ, Nogeira JF Jr, Herman DR: Endoscopic transnasal craniotomy and the resection of craniopharyngioma. Laryngoscope 118:1142-1148, 2008

28. Suzuki J, Katakura R, Kitahara M, Mori T: [The interhemispheric trans-lamina terminalis approach to tumor of anterior part of the third ventricle.] No Shinkei Geka 12:27-34, 1984 (Jpn)

29. Winterkorn JMS, Levy RL, Dinkin MJ: Neuro-ophthalmologic considerations, in Schwartz TH, Anand VK (eds): Endoscopic Pituitary Surgery: Endocrine, Neuro-Ophthalmologic, and Surgical Management. New York: Thieme, 2012, pp 132-145

30. Zanation AM, Snyderman CH, Carrau RL, Kassam AB,
Gardner PA, Prevedello DM: Minimally invasive endoscopic pericranial flap: a new method for endonasal skull base reconstruction. Laryngoscope 119:13-18, 2009

\section{Author Contributions}

Conception and design: Zhang. Acquisition of data: Xie, Sun. Analysis and interpretation of data: $\mathrm{Hu}, \mathrm{Yu}$. Drafting the article: Gu. Critically revising the article: all authors. Reviewed submitted version of manuscript: all authors. Approved the final version of the manuscript on behalf of all authors: Zhang. Study supervision: Zhang, Gu, Li.

\section{Supplemental Information Videos}

Video 1, Media Player. http://mfile.akamai.com/21490/wmv/ digitalwbc.download.akamai.com/21492/wm.digitalsource-naregional/jns13-2842_video_1.asx.

Video 1, Quicktime. http://mfile.akamai.com/21488/mov/ digitalwbc.download.akamai.com/21492/qt.digitalsource-global/ jns13-2842_video_1.mov.

\section{Correspondence}

Xiaobiao Zhang, Department of Neurosurgery, Zhongshan Hospital of Fudan University, 180 Fenglin Rd., Shanghai 200032, People's Republic of China. email: zsneurosurgey@gmail.com. 